\title{
Erratum zu: Soziologie der Mittelschicht
}

\section{Max Keck}

Online publiziert: 19. August 2021

(C) Der/die Autor(en) 2021

\section{Erratum zu:}

\section{Köln Z Soziol 2020}

https://doi.org/10.1007/s11577-020-00707-X

Der Artikel Soziologie der Mittelschicht von Max Keck wurde ursprünglich Online First ohne „Open Access“ auf der Internetplattform des Verlags publiziert. Nach der Veröffentlichung in Bd. 72 Heft 3 pp. 503-507 hatten sich der Autor für eine „Open Access“-Veröffentlichung entschieden. Das Urheberrecht des Artikels wurde deshalb in (C) Der/die Autor(en) 2021 geändert. Dieser Artikel ist jetzt unter der Creative Commons Namensnennung 4.0 International Lizenz veröffentlicht, welche die Nutzung, Vervielfältigung, Bearbeitung, Verbreitung und Wiedergabe in jeglichem Medium und Format erlaubt, sofern Sie den/die ursprünglichen Autor(en) und die Quelle ordnungsgemäß nennen, einen Link zur Creative Commons Lizenz beifügen und angeben, ob Änderungen vorgenommen wurden.

Die in diesem Artikel enthaltenen Bilder und sonstiges Drittmaterial unterliegen ebenfalls der genannten Creative Commons Lizenz, sofern sich aus der Abbildungslegende nichts anderes ergibt. Sofern das betreffende Material nicht unter der genannten Creative Commons Lizenz steht und die betreffende Handlung nicht nach gesetzlichen Vorschriften erlaubt ist, ist für die oben aufgeführten Weiterverwendungen des Materials die Einwilligung des jeweiligen Rechteinhabers einzuholen.

Funding Open Access funding enabled and organized by Projekt DEAL.

Die Online-Version des Originalartikels ist unter https://doi.org/10.1007/s11577-020-00707-x zu finden.

\section{Keck ( $\square)$}

Lehrstuhl für Methoden der Sozialstrukturanalyse, Westfälische Wilhelms-Universität Münster Scharnhorststraße 121, 48151 Münster, Deutschland

E-Mail: max.keck@uni-muenster.de 
Open Access Dieser Artikel wird unter der Creative Commons Namensnennung 4.0 International Lizenz veröffentlicht, welche die Nutzung, Vervielfältigung, Bearbeitung, Verbreitung und Wiedergabe in jeglichem Medium und Format erlaubt, sofern Sie den/die ursprünglichen Autor(en) und die Quelle ordnungsgemäß nennen, einen Link zur Creative Commons Lizenz beifügen und angeben, ob Änderungen vorgenommen wurden.

Die in diesem Artikel enthaltenen Bilder und sonstiges Drittmaterial unterliegen ebenfalls der genannten Creative Commons Lizenz, sofern sich aus der Abbildungslegende nichts anderes ergibt. Sofern das betreffende Material nicht unter der genannten Creative Commons Lizenz steht und die betreffende Handlung nicht nach gesetzlichen Vorschriften erlaubt ist, ist für die oben aufgeführten Weiterverwendungen des Materials die Einwilligung des jeweiligen Rechteinhabers einzuholen.

Weitere Details zur Lizenz entnehmen Sie bitte der Lizenzinformation auf http://creativecommons.org/ licenses/by/4.0/deed.de.

Max Keck M. A., Wissenschaftlicher Mitarbeiter am Lehrstuhl für Methoden der Sozialstrukturanalyse der Westfälischen Wilhelms-Universität Münster. Forschungsschwerpunkte: Armutsforschung, Sozialstrukturanalyse, soziale Ungleichheit und Methoden. Aktuelle Publikationen: Armutsgruppen - Die Ungleichheit der Armen in Deutschland. Reihe: Sozialstrukturanalyse. Springer (im Erscheinen). Wer wählt die AfD? Experimente mit einer quasi-qualitativen Analyse quantitativer Mikrodaten des Sozioökonomischen Panels (SOEP) (als Hrsg. mit B. Görgen, T. Minas, I. Rommel, S. Stockmann). https://doi.org/10. $17879 / 99019647619$ 